\title{
The Effect of Pelvic Compression Belt on the Strength of Hip Muscle and EMG Activity in Individuals with Sacroiliac Joint Pain during Prone Hip Extension
}

\author{
Jae-hong Choi, PT, BHSc. ${ }^{1}$; Jae-seop Oh, PT, Ph.D. ${ }^{1}$; Moon-hwan Kim, PT, Ph.D. ${ }^{2}$ \\ ${ }^{1}$ Department of Physical Therapy, Inje University, Gimhae, South Korea \\ ${ }^{2}$ Department of Rehabilitation Medicine, Wonju Severance Christian Hospital, Wonju, South Korea
}

Background Pelvic compression belt passively stabilized the sacroiliac joint via application of a compression force, thereby having a possibility to affect hip muscle strength.

Purpose We investigated the effects of pelvic compression belts on the strength of hip extensor and the electromyographic (EMG) activities of latissimus dorsi and erector spinae during isometric prone hip extension with knee extension and prone hip extension with knee flexion.

Study design Comparative, repeated measures design.

Methods We recruited 15 patients with sacroiliac joint pain. All performed isometric prone hip extension with knee extension with and without a pelvic compression belts at a hip extension of $10^{\circ}$. Strength of hip extensor were measured using a load cell, and the muscle activities of the contralateral latissimus dorsi and erector spinae muscles measured using surface EMG.

Results Strength of hip extensor with a pelvic compression belts increased significantly compared to without a pelvic compression belts $(p<0.001)$ as did the EMG activity of the contralateral latissimus dorsi $(p<0.05)$. However, the EMG activity of the contralateral erector spinae did not change significantly $(p>0.05)$.

Conclusions We recommend using of a pelvic compression belts by sacroiliac joint pain patients increased the strength of hip extensor and muscle activity of contralateral latissimus dorsi.

Key words Hip extension; Latissimus dorsi; Muscle strength; Pelvic compression belt; Sacroiliac joint pain.

\section{INTRODUCTION}

The articular surfaces of the sacroiliac joint (SIJ) are relatively flat and aligned close to the vertical plane. ${ }^{1}$ Flat joint surfaces are optimal for load transfer. ${ }^{2}$ However, alignment close to the vertical plane confers vulnerability to vertical shear forces caused by gravity, ${ }^{3}$ triggering SIJ instability that is attributable to creep of the long, dorsal sacroiliac and sacrotuberous ligaments under prolonged loads. ${ }^{4}$ Sub-optimal SIJ stability is associated with lumbopelvic, ${ }^{5}$ groin, ${ }^{6}$ hamstring, ${ }^{7}$ and/or low back pain (LBP). ${ }^{8,9}$
JMST

2019; 3(1): 14-21

Published Online Jun 30,2019

pISSN 2635-8573 eISSN 2635-8581

Article History Received 04 April 2019 Revised 04 April 2019 (1st) Revised 10 May 2019 (2nd) Accepted 10 May 2019

\section{CONTACT}

agafimu@hanmail.net Moon-hwan Kim, Department of Rehabilitation Medicine, Wonju Severance Christian Hospital, Wonju, Korea This is an Open-Access article
distributed under the terms of
the Creative Commons Att-
ribution Non-Commercial Li-
cense (http://creativecommons.
org/licenses/by-nc/4.0) which
permits unrestricted non-co-
mmercial use, distribution,
and reproduction in any me-
dium, provided the original work is properly cited.
The prevalence of sacroiliac joint pain (SIJP) is $13-30 \%$ in patients with non-specific LBP. ${ }^{8,10}$ Therefore, numerous efforts have been made to enhance SIJ stability. Effective SIJ load transfer and stability requires optimal passive, active, and neuromuscular joint control. ${ }^{1,11,12}$ These functions vary among individuals by anatomical articular stability (form closure) and neuromuscular stability (force closure) during performance of various activities. ${ }^{13}$ In clinical practice, force closure is reinforced via strengthening of pelvic and trunk muscles, including the gluteus maximus (GM), biceps femoris (BF), latissimus dorsi (LD), 
and erector spinae (ES). ${ }^{5,14}$ Form closure is reinforced via passive support, including a pelvic compression belt (PCBs).

Muscles engaging in forced closure are evaluated in the prone hip extension (PHE) test, which measures SIJ load transfer, ${ }^{15,16}$ strength of hip extensor, ${ }^{17}$ and the recruitment patterns of the hip extensors and trunk muscles. ${ }^{18,19}$ In previous studies, the PHE test was performed only under knee extension (PHE-KE), because the activity and recruitment pattern of the hip joint extensor muscles were of interest, and not muscle strength. However, as the PHE-KE test indexes both GM and BF status, it may be difficult to evaluate GM weakness because of $\mathrm{BF}$ compensation. ${ }^{20}$ Therefore, it is necessary to evaluate PHE-KE and PHEknee flexion (PHE-KF) separately.

Several studies have shown that PCBs enhance form closure. Jung et al. ${ }^{21}$ found that, compared to asymptomatic individuals, the $\mathrm{BF}$ electromyographic (EMG) amplitude was significantly reduced in those with SIJP who used PCBs. Furthermore, the GM reaction time was significantly decreased during one-leg standing. Kim et al. ${ }^{22}$ compared healthy and LBP groups using PCBs during PHE; muscle activity of trunk was reduced significantly more in LBP subjects than in healthy controls. Mens et al. ${ }^{23}$ and Yoon et al. ${ }^{24}$ confirmed that PCBs increased strength of hip flexor and adductor, and muscle activity of abdominal. However, these studies did not explore strength of hip extensor or muscle activity of trunk.

Previous studies found that PCBs passively stabilized the SIJ via application of a compression force, ${ }^{25,26}$ thereby significantly affecting hip muscle strength..$^{23,24,37}$ In particular, PCBs can be applied during PHE to evaluate SIJ load-transfer function, but we instead sought to investigate changes in muscle activity. In those with SIJP, strength of hip extensor is important because the proximal GM is attached to the SIJ, affording stability through application of compression across the joint. ${ }^{14}$ The GM is very active during abrupt limb loading; the SIJ must be stable. SIJP patients exhibit GM weakness and muscle activity delay, triggering compensation by the $\mathrm{BF}^{2,28}$ that can increase SIJP and cause LBP. ${ }^{29}$ However, no study has yet explored the effects of PCBs on strength of hip extensor. Arab et al. ${ }^{28}$ confirmed that the GM was weak in those with SIJP, but used only a pressure meter for measurement. Strength of hip extensor is preferentially measured using a hand-held dynamometer (HHD) or isokinetic dynamometer, but these instruments are difficult to employ clinically, being unreliable and expensive. Recently, tensiometers have been used to measure strength; tensiometers are both very reliable and portable. ${ }^{27}$ Therefore, we objectively measured changes in strength of hip extensor and muscle activity of trunk when SIJP patients wore PCBs during PHE.

\section{METHODS}

\section{Subjects}

We enrolled 15 female volunteers with SJIP, aged 20-60 years, in Bokum general hospital of Gimhae city (Table 1). The inclusion criterion was showing at least three of a possible six positive reactions on SIJP provocation testing (distraction, compression, thigh thrust, Gaenslen's response, sacral thrust, and the drop test); all tests exhibit acceptable inter-rater reliability. ${ }^{10,30-32}$ The exclusion criteria were an unwillingness to participate; only midline or symmetrical pain above the L5 level; any clear sign of nerve root compression (a complete motor or sensory deficit); a history of spinal surgery; a history of spinal, pelvic, or lower extremity fracture; prior hospitalization for trauma or a motor vehicle accident; hip or knee dysfunction; pregnancy; and/or any systemic disease (arthritis, tuberculosis, liver disease, or kidney failure); such subjects were deemed too frail for complete physical examination. ${ }^{33}$

The sample size was calculated using a pilot study that revealed significant increase in strength of hip extensor and muscle activity of the contralateral LD. Power analysis indicated that at least six participants would be required to achieve a power of 0.80 and an effect size of 1.213 at a significance level of 0.05 prior to the experiment, all participants were provided with a thorough explanation of the intervention protocol and voluntarily agreed to participate. All signed informed consent forms were approved by the Inje University Ethics Committee for Human Investigations (approval no. INJE 2017-09-014-003).

\section{Force of hip extensor}

Force of hip extensor was measured using fixed customdesigned instrumentation assessing the isometric PHE-KE and PHE-KF forces. A load cell (RSBA-50L; Radian, Seoul,

Table 1. General characteristics of subjects $(n=15)$

\begin{tabular}{cc}
\hline Characteristic & Mean \pm SD \\
\hline Age (years) & $46.13 \pm 11.42$ \\
Height $(\mathrm{cm})$ & $159.13 \pm 3.20$ \\
Body weight $(\mathrm{kg})$ & $49.69 \pm 4.33$ \\
BMI $\left(\mathrm{kg} / \mathrm{m}^{2}\right)$ & $31.47 \pm 2.81$ \\
VAS & $5.20 \pm 1.01$ \\
\hline
\end{tabular}

Abbreviations: BMI, body mass index; VAS, visual analog scale. 
Korea) linked to a digital indicator displaying the force was connected to a board (a $702 \times 300 \times 18$-mm plate; Figure. 1). The detectable force range was $0-50 \mathrm{~kg}$ at a resolution of $0.1 \mathrm{~kg}$ and the precision was $\pm 0.3 \mathrm{~kg}$. The sampling frequency was $100 \mathrm{~Hz}$. In our previous study, this instrument exhibited excellent intra- and inter-rater correlations (intraclass correlation coefficient 0.97) when used to measure isometric strength. ${ }^{27,34}$ The maximal force generated during isometric PHE-KE and PHE-KF after application of force to the load cell was automatically recorded.

\section{Muscle activity of trunk}

EMG data were recorded from the contralateral LD and ES during isometric PHE-KE and PHE-KF using a surface EMG system (Trigno Wireless; Delsys, Boston, MA, USA). The signals were amplified and band-pass filtered (20-450 $\mathrm{Hz}$ ) prior to digital recording at 2,000 $\mathrm{Hz}$, and root mean square (RMS) values then calculated. We used two maneuvers to normalize EMG activity: maximal and submaximal voluntary isometric contractions. ${ }^{35}$ Pre-test, we confirmed that, under both conditions, the values were equal. However, when the ES was subjected to maximal isometric contraction, SJIP individuals developed acute pain. Therefore, the submaximal method was judged appropriate for ES evaluation. Trunk muscle normalization exhibited excellent within-day reliability in both healthy controls and SJIP individuals. $^{22}$

To minimize skin impedance before EMG electrodes were attached, hair was removed and the skin cleaned with

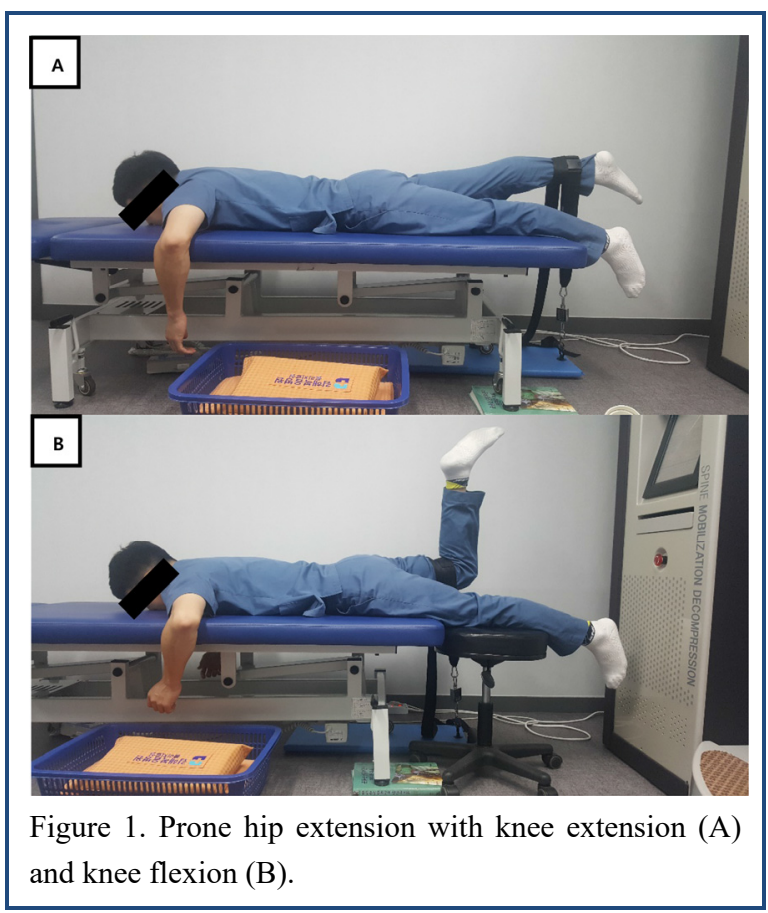

alcohol-saturated cotton. EMG data were collected bilaterally from the LD ( $4 \mathrm{~cm}$ below the inferior tip of the scapula at half the distance between the spine and lateral edge of the torso) and the ES ( $2 \mathrm{~cm}$ lateral to the spinous process at the L1 level and parallel to the spine). ${ }^{36}$

All muscles were tested in the PHE position. The LD maximal isometric contractions were measured when manual resistance was applied. ${ }^{17}$ Each LD was tested with the subject's arms at the sides, and the shoulders internally rotated to create a palm-up position. Resistance was then applied to the forearm. During submaximal voluntary ES isometric contraction, the subject lifted both knees $5 \mathrm{~cm}$ off the examination table, flexed them at $90^{\circ}$, and held that position for $5 \mathrm{~s} .{ }^{37}$ Each maximal and submaximal isometric contraction maneuver was performed twice for $5 \mathrm{~s}$ each time, and the muscle activity of average during the middle 3 $\mathrm{s}$ of both trials was used for normalization. The EMG results were normalized to the maximal and submaximal EMG RMS values calculated from EMG signals obtained during voluntary isometric contraction of each muscle.

\section{Use of the PCBs}

A PCBs (SI-LOC; OPTP, Minneapolis, USA) was worn below the anterosuperior iliac spine (ASIS) ${ }^{25}$ and fastened firmly to a belt (Figure 2). The device was constructed of non-elastic material with Velcro ends, and was $5 \mathrm{~cm}$ wide at the front and back, and $8 \mathrm{~cm}$ wide at the sides. The tightness was adjusted by a physiotherapist experienced with SIJP patients; no patient complained of pain or discomfort.

\section{Experimental procedures}

The maximal isometric PHE-KE and PHE-KF were measured with and without the PCBs (in a random order). A non-elastic belt connected to the load cell was placed on the Achilles tendon during PHE-KE, and behind the knee during PHE-KF (Figure 1). The opposite end of the belt was fixed vertically to the ground to maintain a consistent belt length during PHE-KE and PHE-KF, facilitating isometric

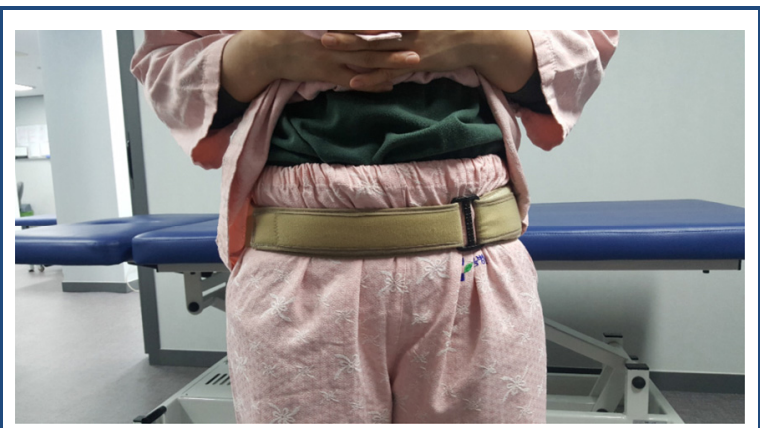

Figure 2. Application of the pelvic compression belt. 
contraction when the affected hip joint extended from neutral to about $10^{\circ}$. Also, to restrict unwanted trunk movement, individuals lay prone with $90^{\circ}$ shoulder abduction and $90^{\circ}$ elbow flexion. Isometric PHE-KE and PHE-KF were performed for $5 \mathrm{~s}$ three times, with a 1 -min break between measurements.

\section{Statistical analyses}

The three mean muscle forces measured during isometric PHE-KE and PHE-KF were analyzed, as were the means of three measurements of contralateral LD and ES activities. Data were analyzed using SPSS software (ver. 18.0; SPSS Inc., Chicago, IL, USA) and are expressed as means \pm SD. Two-way repeated analysis of variance (ANOVA) was used for within-group comparisons, with and without the PCBs. If significant interactions were evident between PHE-KE and PHE-KF, the post-hoc paired t-test was performed. A $p$ value $<0.05$ was considered to reflect statistical significance.

\section{RESULTS}

Without and with the PCBs, the PHE-KE force $(6.83 \pm$ 3.17 vs. $8.27 \pm 3.60 \mathrm{~kg}$; difference, $1.44 \mathrm{~kg}$; $99 \% \mathrm{CI}: 1.11-$ $1.76 \mathrm{~kg} ; p<0.001)$ and PHE-KF force $(7.09 \pm 3.85 \mathrm{vs}$. $12.50 \pm 4.38 \mathrm{~kg}$; difference, $5.40 \mathrm{~kg}$; $99 \%$ CI: $5.00-5.81 \mathrm{~kg}$; $p<0.001)$ were significantly higher when the PCBs was worn (Table 2, Figure 3). The paired t-test indicated that the force was $3.34 \mathrm{~kg}$ higher (99\% CI: $2.63-4.91 \mathrm{~kg}$ ) during PHE-KF than PHE-KE $(p<0.001)$ (Table 2). The post-hoc paired $t$-test showed that PHE-KE and PHE-KF forces without a PCBs did not differ significantly $(p>0.05)$, but did when the PCBs was worn $(p<0.05)$.

When the PCBs was not worn during PHE-KE, the EMG data varied $(28.98 \pm 3.12$ vs. $39.94 \pm 5.03 \mathrm{mV}$; difference, $11.00 \mathrm{mV}$; $99 \% \mathrm{CI}: 5.30-16.71 \mathrm{mV} ; p<0.05)$, as was also true during PHE-KF (31.66 \pm 3.97 vs. 53.68 \pm 6.92 ; difference, $22.02 \mathrm{mV}$; 99\% CI: 13.23-30.80 mV; $p<0.05)$; the muscle activity of the contralateral LD also significantly increased

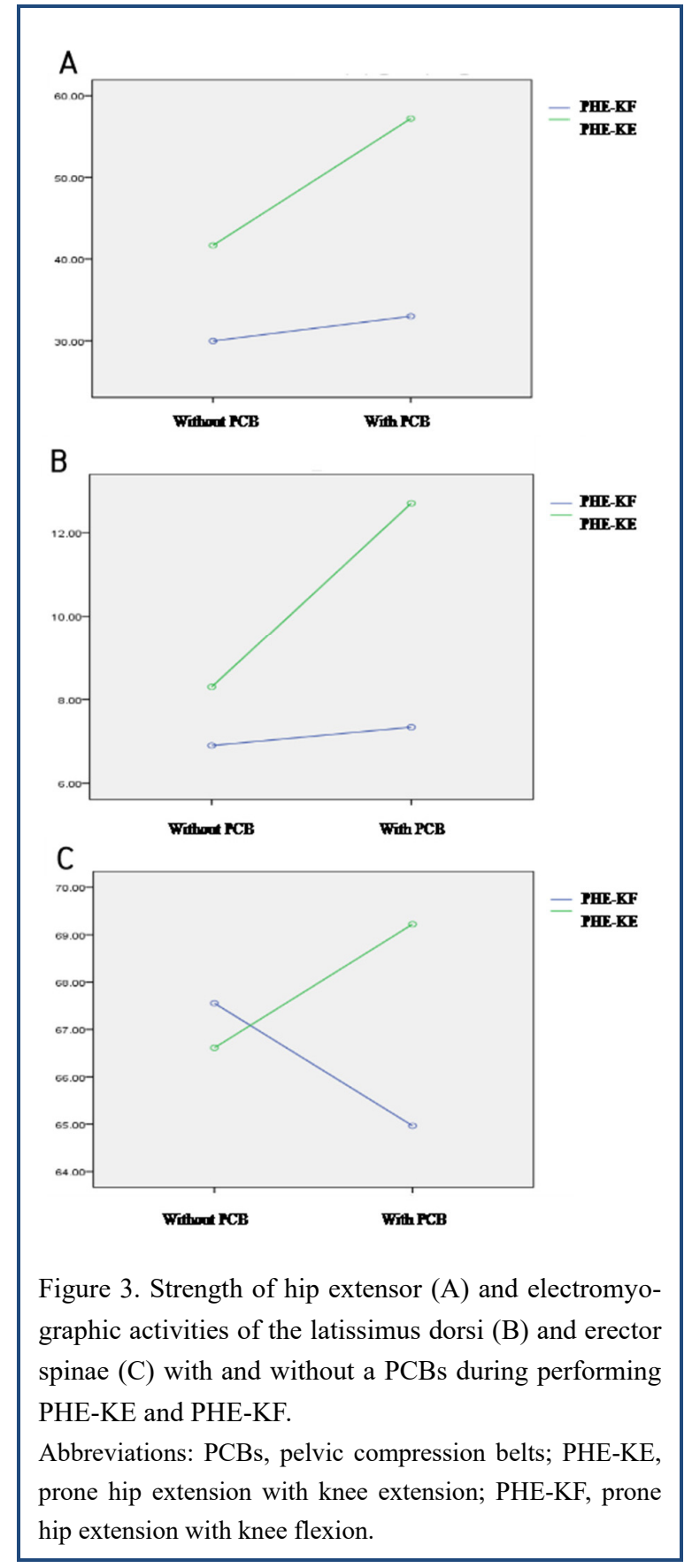

Table 2. Force of hip extensor with and without the pelvic compression belt during performing PHE-KE and PHE-KF

\begin{tabular}{cccccc} 
& & & & $(n=15)$ \\
\hline & Without PCBs & With PCBs & $\begin{array}{c}\text { Within-posture } \\
\text { difference }(99 \% \text { CI })\end{array}$ & $\begin{array}{c}\text { Between-posture } \\
\text { difference }(99 \% \text { CI })\end{array}$ & $p$-value \\
\hline PHE-KE & $6.83 \pm 3.17$ & $8.27 \pm 3.60$ & $1.44(1.11,1.76)$ & $3.34(2.63,4.19)$ & $<0.001$ \\
\hline PHE-KF & $7.09 \pm 3.85$ & $12.50 \pm 4.38$ & $5.40(5.00,5.81)$ & & \\
\hline
\end{tabular}

Values are means $\pm \mathrm{SD}$.

$p<0.001$.

Abbreviations: CI, confidence interval; PCBs, pelvic compression belts; PHE-KE, prone hip extension with knee extension; PHE$\mathrm{KF}$, prone hip extension with knee flexion. 
(Table 3, Figure 3). The paired t-test indicated that the mean difference of $16.51 \mathrm{mV}$ (99\% CI: 5.41-27.61 mV) was significantly greater during PHE-KF than PHE-KE $(p<0.05)$ (Table 3). However, the muscle activity of the contralateral ES did not differ significantly ( $p>0.05$; Table 4 , Figure 3 ).

\section{DISCUSSION}

We explored whether a PCBs passively stabilized the SIJ by improving the strength of hip extensor and LD and ES activities during isometric PHE-KE and PHE-KF. The PCBs significantly improved strength of hip extensor $(p<0.001)$, and also significantly increased activity of LD $(p<0.05)$ but not activity of ES $(p>0.05)$. To stabilize the SIJ, the pelvis and hip muscles contract, forcing closure mediated by a compressive force between the ilium and sacrum. ${ }^{19,38,39}$ This represents a particularly important role of the muscles and the fascia; the relevant muscles are the proximal GM, the BF, and the ES; the thoracolumbar fascia is primarily involved. ${ }^{5}$ Also, appropriate force closure requires SIJ stability. ${ }^{21,22,29}$ SIJ instability decreased when a PCBs was worn 25,26 the PCBs complemented the force closure caused by muscular contraction, by increasing SIJ passive stability (form closure) ${ }^{21}$ thereby alleviating SIJP. In addition, $\mathrm{PCBs}$ aided muscle contraction by increasing intramuscular pressure (IMP), in turn affecting muscle strength and activity. ${ }^{40,41}$

Yoon et al. ${ }^{24}$ reported that PCBs application during the active straight leg raise (ASLR) task significantly increased hip flexor muscle strength by enhancing passive stability of the lumbopelvic region, thereby suppressing muscular action form triggering unnecessary compensation, and thereby ultimately promoting hip flexion. The data of Mens et al., ${ }^{23}$ Park et al., ${ }^{39}$ and Kang et al. ${ }^{27}$ support this argument. However, in previous studies, hip flexor and adductor strength were assessed by the extent of PCBs wear; strength of hip extensor was not explored. Recently, Arab et al. ${ }^{28}$ suggested that the GM was weak in those with SIJP, but used only a pressure meter to collect data; real muscle strength was not measured. Pressure meter data are subjective, reflecting the pressure imposed by the examiner. Kim et al. ${ }^{19}$ showed that muscle activity of hip extensor changed during PHE. Muscle strength was measured via manual strength measurement using an HHD; this is common in clinical practice. However, as strength is assessed as the manual resistance to the examiner, if the patient is stronger than the examiner, the data will be erroneous. ${ }^{42}$ Thus, we measured objective strength of hip extensor during isometric PHE-KE and PHE-KF in patients wearing or not wearing a non-elastic belt.

Table 3. Electromyographic activities of the latissimus dorsi with and without pelvic compression belt during maximal isometric PHE-KE and PHE-KF.

$(n=15)$

\begin{tabular}{rccccc}
\hline Position & Without PCBs & With PCBs & $\begin{array}{c}\text { Within-posture } \\
\text { difference }(99 \% \text { CI) }\end{array}$ & $\begin{array}{c}\text { Between-posture } \\
\text { difference }(99 \% \text { CI })\end{array}$ & $p$-value \\
\hline PHE-KE & $28.98 \pm 3.12$ & $39.94 \pm 5.03$ & $11.00(5.30,16.71)$ & $16.51(5.41,27.61)$ & $<0.05$ \\
PHE-KF & $31.66 \pm 3.97$ & $53.68 \pm 6.92$ & $22.02(13.23,30.80)$ & & \\
\hline
\end{tabular}

Values are means $\pm \mathrm{SD}$.

$p<0.05$.

Abbreviations: CI, confidence interval; PCBs, pelvic compression belts; PHE-KE, prone hip extension with knee extension; PHE$\mathrm{KF}$, prone hip extension with knee flexion.

Table 4. Electromyographic activities of the erector spinae with and without pelvic compression belt during maximal isometric PHE-KE and PHE-KF

$(n=15)$

\begin{tabular}{rccccc}
\hline Position & Without PCBs & With PCBs & $\begin{array}{c}\text { Within-posture } \\
\text { difference }(99 \% \mathrm{CI})\end{array}$ & $\begin{array}{c}\text { Between-posture } \\
\text { difference (99\% CI) }\end{array}$ & $p$-value \\
\hline PHE-KE & $68.45 \pm 3.43$ & $66.87 \pm 3.51$ & $-1.57(-1.34,-1.81)$ & $1.23(-4.10,6.57)$ & $>0.05$ \\
PHE-KF & $66.19 \pm 4.10$ & $70.23 \pm 3.73$ & $4.04(5.13,2.95)$ & & \\
\hline
\end{tabular}

Values are means $\pm \mathrm{SD}$.

$p<0.05$.

Abbreviations: CI, confidence interval; PCBs, pelvic compression belts; PHE-KE, prone hip extension with knee extension; PHE$\mathrm{KF}$, prone hip extension with knee flexion. 
The results of previous studies using HHDs, and our results using a non-elastic belt, indicate that PCBs-induced SIJ passive stability promoted action of hip extensor and increased extensor strength. In addition, isometric PHE-KF increased the GM strength more so than isometric PHE-KE increased the hamstring strength; the $\mathrm{PCB}$ reduced reaction time of GM and activity of BF more so than that of the hamstring. ${ }^{21,29}$ The PCBs contacted the GM and increased the IMP, significantly enhancing muscle strength compared to that of the hamstring. ${ }^{40,41}$ Our results are clinically important because the proximal GM stabilizes the $\mathrm{SIJ}^{5}$ and the BF; global muscle strengthening can trigger compensatory LBP. ${ }^{29}$

The activity of the contralateral LD increased significantly when a PCBs was worn during isometric PHE$\mathrm{KE}$ and PHE-KF $(p<0.05)$. However, the activity of the contralateral ES did not change $(p>0.05)$. A PCBs significantly reduced muscle activity of trunk during PHE. ${ }^{19}$ Jung et al. ${ }^{21}$ reported that when the PCBs was worn during one leg standing, the reaction time of the GM and the activity of BF decreased, but the BF reaction time increased. However, we did not schedule a PHE task; rather, we measured maximal muscle strength during the PHE-KE and PHE-KF postures. SIJ stability was increased by the PCBs, as was maximal muscle strength. Thus, PCBs-promoted load-transfer via the SIJ increased the maximal strength and activity of the contralateral LD, and also the IMP, through contact with the contralateral LD; this significantly increased muscle activity. However, activity of ES did not change significantly; the ES was not in contact with the PCBs.

Our study had certain limitations. First, we did not divide subjects into acute and chronic SIJP groups, rendering the SDs relatively high. In future studies, patients should be distinguished on this basis. The second limitation was that we measured only strength of hip extensor and muscle activity of trunk during PHE-KE and PHE-KF. It would be useful to additionally assess the strength of the isolated lateral hamstring, and that of external rotation during hip extension. Finally, we enrolled only 15 subjects; it is thus difficult to generalize our results.

\section{CONCLUSION}

We found that PCBs use during PHE passively stabilized the SIJ, promoting muscle activity of LD and increasing strength of hip extensor. Thus, the PCBs improved load transfer by the SIJ. Also, the PCBs increased muscle strength and activity by compressing muscles. We recommend using of PCBs for patients with SIJP increased the strength of hip extensor and muscle activity of contralateral latissimus dorsi.

\section{Key Points}

Question Can pelvic compression belt change the strength of hip extensor and the electromyographic (EMG) activities of latissimus dorsi and erector spinae during isometric prone hip extension?

Findings Strength of hip extensor increased significantly with compared to without a pelvic compression belts as did the EMG activity of the contralateral latissimus dorsi. However, the EMG activity of the contralateral erector spinae did not change significantly.

Meaning We recommend using of a pelvic compression belts by sacroiliac joint pain patients increased the strength of hip extensor and muscle activity of contralateral latissimus dorsi.

\section{Article information}

Conflict of Interest Disclosures: None.

Funding/Support: None.

Acknowledgment: None.

\section{REFERENCES}

1. Snijders CJ, Vleeming A, Stoeckart R. Transfer of lumbosacral load to iliac bones and legs: part 1: biomechanics of self-bracing of the sacroiliac joints and its significance for treatment and exercise. Clin Biomech. 1993;8(6):285-294.

2. Hungerford B, Gilleard W, Hodges P. Evidence of altered lumbopelvic muscle recruitment in the presence of sacroiliac joint pain. Spine. 2003;28(14):1593-1600.

3. Snijders CJ, Ribbers MT, De Bakker HV, Stoeckart R, Stam HJ. EMG recordings of abdominal and back muscles in various standing postures: validation of a biomechanical model on sacroiliac joint stability. $J$ Electromyogr Kinesiol. 1998;8(4):205-214.

4. Vleeming A, Buyruk HM, Stoeckart R, Karamursel S, Snijders CJ. An integrated therapy: a study of the biomechanical effect of pelvic belts. Am J Obstet Gynecol. 1992;166(4):1243-1247.

5. Vleeming A, Schuenke MD, Sturesson B, Willard FH, The sacroiliac joint: an overview of its anatomy, function and potential clinical implications. J Anat. 2012;221(6): 537-567.

6. Jansen J, Mens J, Backx F, Stam H. Changes in abdominal muscle thickness measured by ultrasound are not associated with recovery in athletes with longstand- 
ing groin pain associated with resisted hip adduction. $J$ Orthop Sports Phys Ther. 2009;39(10):724-732.

7. Panayi S. The need for lumbar-pelvic assessment in the resolution of chronic hamstring strain. J Bodyw Mov Ther. 2010;14(3):294-298.

8. Schwarzer AC, Aprill CN, Bogduk N. The sacroiliac joint in chronic low back pain. Spine. 1995;20(1):31-37.

9. Slipman CW, Sterenfeld EB, Chou LH, Herzog R, Vresilovic E. The predictive value of provocative sacroiliac joint stress maneuvers in the diagnosis of sacroiliac joint syndrome. Arch Phys Med Rehabil. 1998;79:288-292.

10. Maigne JY, Aivaliklis A, Pfefer F. Results of sacroiliac joint double block and value of sacroiliac pain provocation tests in 54 patients with low back pain. Spine. 1996;21(16):1889-1892.

11. Panjabi MM. The stabilizing system of the spine. part I: function, dysfunction, adaptation, and enhancement. $J$ Spinal Disord \& Techniques. 1992;5(4):383-389.

12. Vleeming A, Stoeckart R, Volkers ACW, Snijders CJ. Relation between form and function in the sacroiliac joint: part I: clinical anatomical aspects. Spine. 1990a; 15(2):130-132.

13. De Groot M, Pool-Goudzwaard AL, Spoor CW, Snijders CJ. The active straight leg raising test (ASLR) in pregnant women: differences in muscle activity and force between patients and healthy subjects. Man Ther. 2008;13(1):68-74.

14. Baker PJ, Hapuarachchi KS, Ross JA, Sambaiew E, Ranger TA, Briggs CA. Anatomy and biomechanics of gluteus maximus and the thoracolumbar fascia at the sacroiliac joint. Clin Anat. 2014;27:234-240.

15. Bruno PA, Millar DP and Goertzen DA. Inter-rater agreement, sensitivity, and specificity of the prone hip extension test and active straight leg raise test, Bruno et al. Chiropr Man Therap. 2014;22(1):23.

16. Sahrmann S. Diagnosis and treatment of movement impairment syndromes. 1st ed. 2002. Mosby Inc.

17. Kendall FP, McCreary EK, Provance PG. Muscles: testing and function with posture and pain. 5th ed. Baltimore; 2005.

18. Jull GA, Janda V. Muscles and motor control in low back pain: assessment and management. In Physical therapy of the low back. Churchill Livingstone; 1987.

19. Kim JW, Kim OY, Kim TH, An DH, Oh JS. Effects of external pelvic compression on trunk and hip muscle EMG activity during prone hip extension in females with chronic low back pain. Man Ther. 2014;19:467471.

20. Hislop HJ. Daniels and Worthingham's muscle testing. 8th ed. Elsever; 2007.

21. Laslett M. Evidence-based diagnosis and treatment of the painful sacroiliac joint. J Man Manip Ther. 2008; 16(3):142-152.

22. Kim JW, Kang MH, Oh JS. Patients with low back pain demonstrate increased activity of the posterior oblique sling muscle during prone hip extension. PMR. 2014; 6:400-405.

23. Mens JM, Damen L, Snijders CJ, Stam HJ. The mechanical effect of a pelvic belt in patients with pregnancy-related pelvic pain. Clin Biomech. 2006b; 21(2):122-127.

24. Yoon DJ, Kim SY, Lee EH, et al. Effect of an application of pelvic compression belt on the strength of hip flexor in healthy young adult. Phys Ther Korea. 2008;15(4):34-35.

25. Damen L, Spoor CW, Snijders CJ, Stam HJ. Does a pelvic belt influence sacroiliac joint laxity? Clin Biomech. 2002;17(7):495-498.

26. Oh JS, Kang MH, Dvir Z, Reproducibilityof isometric shoulder protractionand retraction strength measurements in normal subjectsand individualswith winged scapula. J Shoulder Elbow Surg. 2016;25(11):18161823.

27. Kang MH, Oh JS. Effects of a pelvic belt on hip muscle forces and abdominal muscle activities during isometric hip adduction and abduction. Phys Ther Korea. 2017; 24(2):19-26.

28. Arab AM, Nourbakhsh MR. The relationship between hamstring length and gluteal muscle strength in individuals with sacroiliac joint dysfunction. J Man Manip Ther. 2011;19(1):5-10.

29. Hossain M, Nokes LDM. A model of dynamic sacroiliac joint instability from malrecruitment of gluteus maximus and biceps femoris muscles resulting in low back pain. Med Hypotheses. 2005;65:278-281.

30. Cyriax J. Textbook of orthopaedic medicine. Volume one: diagnosis of soft tissue lesions. 6th ed. London: Balliere Tindall; 1975;546-554.

31. Laslett M, Young S, Aprill C, McDonald B. Diagnosis of sacroiliac joint pain: validity of individual provocation tests and composites of tests. Man Ther. 2005;10: 207-218.

32. Robinson HS, Brox JI, Robinson R, Bjelland E, Solem $\mathrm{S}$, Telje $\mathrm{T}$. The reliability of selected motion- and pain provocation tests for the sacroiliac joint. Man Ther. 2007;12:72-79.

33. Laslett M. Evidence-based diagnosis and treatment of the painful sacroiliac joint. J Man Manip Ther. 2008; 16(3):142-152. 
34. Oh JS, Kang MH, Dvir Z, Reproducibility of isometric shoulder protractionand retraction strength measurements in normal subjectsand individualswith winged scapula. J Shoulder Elbow Surg. 2016;25(11):18161823.

35. Pirouzi S, Hides J, Richardson C, Darnell R, Toppenberg R. Low back pain patients demonstrate increased muscle activity of hip extensor during standardized submaximal rotation efforts. Spine. 2006;31(26):999-1005.

36. Criswell E. Introduction to surface electromyography. 2nd ed. Jones and Bartlett Publishers; 2010.

37. Dankaerts W, O'Sullivan PB, Burnett AF, Straker LM, Danneels LA. Reliability of EMG measurements for trunk muscles during maximal and sub-maximal voluntary isometric contractions in healthy controls and CLBP patients. J Electromyogr Kinesiol. 2004;14(3): 333-342.

38. Lee D. The pelvic girdle. Churchill Livingstone; 2004.
39. Park KM, Kim SY, Oh DW. Effects of the pelvic compression belt on gluteus medius, quadratus lumborum, and lumbar multifidus activities during side-lying hip abduction. J Electromyogr Kinesiol. 2010;20(26): 1141-1145.

40. Maton B, Thiney G, Ouchene A. Intramuscular pressure and surface EMG in voluntary ankle dorsal flexion: influence of elastic compressive stockings. J Electromyogr Kinesiol. 2006;16(3):291-302.

41. Weijie Fu, Yu Liu, Songning Zhang, Xiaojie Xiong, Shutao Wei. Effects of local elastic compression on muscle strength, electromyographic, and mechanomyographic responses in the lower extremity. $J$ Electromyogr Kinesiol. 2012;22(1):44-50.

42. Thorborg K. Hip- and knee-strength assessments using a hand-held dynamometer with external belt-fixation are inter-tester reliable. Knee Surg Sports Traumatol Arthrosc. 2013;21:550-555. 